Sección Tres: Experiencias, reseñas, debates e informes

Educación y Exclusión social

\title{
Reseña del libro Miradas y voces de futuros maestros. Colección Horizontes. Barcelona: Octaedro ${ }^{1}$
}

\author{
Sandra García Delgado \\ Licenciada en Pedagogía. \\ sandragarciadelgado@hotmail.com
}

\section{Reseña}

Este libro se enmarca dentro del programa de innovación y mejora docente promovido por el Vicerrectorado de investigación de la Universidad de Cádiz. En él un equipo de profesoras y

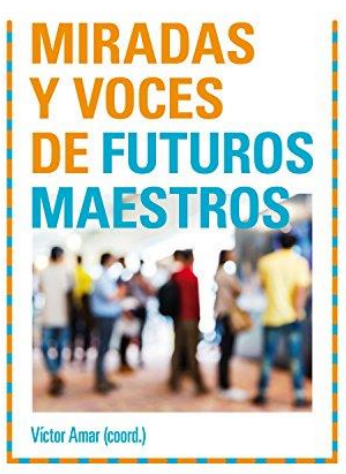

octaedro $\$$ profesores de distintas áreas de la facultad de Educación de la UCA se embarcan en una investigación focalizada en experiencias de futuros maestros desde varios rincones de la provincia. El elenco de investigadores que en distintos capítulos conforman este libro son: Sánchez Torrejón, B.; Vázquez Domínguez, C.; Parrado Collantes, M., Romero Oliva, M. F. y Trigo Ibáñez, E.; Bernal Acuña, M. J.; Gómez Ruiz, M. A.; Segura Caballero, N.; Serrano Díaz, N. y Del Águila Ríos, Y.; Pérez-González, A. B.; Amar, V. y Peláez, R.

Los antecedentes de esta creación tienen su génesis en la obra "Miradas y voces de maestros jubilados" que vio la luz por primera vez en 2016 y en la que se realizaba una investigación narrativa de la práctica docente de maestros y maestras que educaron generaciones desde la época de la transición. Coordinado de la misma manera por Víctor Amar y siguiendo la misma metodología, se aventuran en este nuevo ejemplar en el que cambian las vivencias de maestros jubilados por la de jóvenes estudiantes de la profesión de magisterio.

El objetivo de tal hazaña no es otro que compartir las voces de los estudiantes para, como apuntan en el volumen, "comprender y dar a comprender, conocer y analizar" con la pretensión de reflexionar y mejorar en la práctica docente. Sin embargo, la metodología utilizada dista mucho de sobrecargar al

1Recibido: 05/10/2018 Evaluado: 07/10/2018 Aceptado: 10/10/2018 
lector con cifras, medias y covarianzas; se realiza a través de un enfoque cualitativo, de índole biográfico-narrativo y basado en historias de vida (Pujadas, 2000). Y es por este sendero por el que el lector consigue vislumbrar el porqué del título del libro, pues encontramos vivencias, miradas, voces y caricias hacia una profesión tan maltratada como es la labor docente.

Este volumen se estructura en prólogo, prefacio, nueve artículos que conforman un capítulo cada uno, posfacio y su correspondiente índice dedicados a escudriñar las competencias que debe adquirir un buen docente en la facultad, que a su vez serán requisito indispensable para su futuro desempeño en la labor educativa. La educación está presente en las civilizaciones desde tiempo inmemorables y a menudo, especialmente con los cambios sociales ocurridos en las últimas décadas, se nos plantea el debate: ¿qué deben aprender los futuros maestros y maestras en el grado? ¿Con qué competencias deben salir de la universidad? Cientos de estudios se han realizado al respecto, se ha investigado, se ha leído y se ha concluido pero habitualmente se ha dejado fuera a los propios partícipes. Este libro es un espacio para ellas y ellos, para darle voz a sus aspiraciones, inquietudes y deseos en este ámbito.

A lo largo del ejemplar recorremos distintos puntos de la provincias de Cádiz y Sevilla de la mano de nuestros protagonistas, los alumnos y alumnas entrevistados, y observamos a través de sus miradas el panorama educativo. Las inquietudes en cada persona participante han sido diferentes, aunque sí que coincidían en algunos sujetos. Echan de menos métodos más innovadores, critican con ahínco el aprendizaje memorístico que aún hoy se promueve en las universidades según qué docente, sugieren una mejor organización en los contenidos de algunas asignaturas ya que algunas se solapan, hacen mención a la necesidad de más recursos en las aulas, más posibilidad de experimentar lo aprendido... Sin embargo, más allá de estas premisas (que quizás eran previsibles) manifiestan su preocupación por saber transmitir unos valores adecuados a sus futuros discentes, cuestiones que se enmarcan dentro de lo que conocemos como curriculum oculto, y lo fundamentan en que como dice Lopes Louro (2001) "no debemos olvidar que la escuela jamás deja de educar, educa cuando dice y también cuando no dice."

En alguna de las historias de vida se puede entrever perfectamente cómo el contexto nos educa a veces reproduciendo valores machistas, racistas, homófobos, etc.; en cualquier caso discriminantes, y nuestros protagonistas ponen de manifiesto que esos principios no pueden reproducirse en el aula, sino que hay que fomentar el pensamiento crítico y promover actitudes y valores positivos entre los educandos a los que se van a enfrentar en un futuro próximo.

Otra de las cuestiones que plantean es el factor motivación entre el profesorado. Afirman que el magisterio debe ser una carrera vocacional y que es su tarea, como agentes educativos, saber motivar a sus alumnos y alumnas para conseguir sus metas.

En definitiva, proponen una visión más humanista de la enseñanza.

Alegan que la profesión docente es un proceso de metamorfosis (tanto para el docente como para el alumno) en el que se debe formar al alumnado dentro de los cánones de libertad de pensamiento, lo que implica facilitarles estrategias, herramientas y un amplio bagaje de conocimientos que posibiliten el pensamiento crítico. De esta forma se atajaría esa reproducción de roles e ideas tradicionales a las que nos referíamos anteriormente. También apuestan por promover una metodología más activa y participativa en la que el educando "aprenda viviendo y haciendo". 
En resumen, los autores crearon este ejemplar porque, como ellos y ellas mismos defienden, "conociendo a nuestro alumnado seríamos capaces de conocernos a nosotros mismos (como comunidad) y realizar una mejor y pertinente práctica educativa". Y en efecto no les dejaron indiferentes.

La sociedad tal y como la conocemos está en constante transformación y eso supone un reto para nuestro gremio, que debe amoldarse a estos cambios continuos. Así lo defiende Fernández Enguita (2017a) cuando sostiene que "La adaptación al nuevo entorno global, digital y postindustrial y multicultural requiere una respuesta elaborada, ambiciosa y de amplio respaldo". Y estos alumnos lo tienen claro: conciben una visión de escuela transformadora, que ayude a superar estereotipos pasados, con un enfoque más humanista, en la que el proceso educativo esté centrado en el alumno, en sus necesidades y en sus intereses.

En líneas generales el lector se enfrenta a un ejemplar de fácil y apacible lectura. Resulta muy interesante que en cada cada artículo (capítulo) se vayan exponiendo los testimonios personales de uno o varios alumnos, y cómo, partiendo de entrevistas similares en cada capítulo la diversidad de las respuestas de los sujetos es imperante.

Destacable la labor de estas profesoras y profesores, que lejos de temer la opinión de su alumnado, la utilizan para nutrirse y superarse en su praxis docente. Encomiable la fuerza con la que viene esta nueva generación de maestros y maestras de vocación, que tintan de humanidad procesos que históricamente han tenido una finalidad puramente académica y cognitiva. Sin duda cambios transgresores nos esperan y ellos y ellas están preparados para afrontar y luchar los desafíos que se les presenten.

Para finalizar, me quedo con una premisa que aparece en el posfacio: "la voz es difícil callarla. Es muy poderosa". Que así sea.

\section{Referencias}

Amar Rodríguez, V. (Coord.) (2016). Miradas y voces de maestros jubilados: una investigación desde la narrativa. Granada: Ediciones Octaedro Andalucía.

Ballarín Domingo, P. (2001). La educación de las mujeres en la España contemporánea (siglos XIX$X X)$. Madrid: Síntesis Educación.

Bolívar, A. Et al. (1998). La investigación biográfico-narrativa en educación. Guía para indagar en el campo. Granada: FORCE.

Bolívar, A. (2002). ¿De nobis ipsis silemus? Epistemología de la investigación biográfico narrativa en educación. Revista Electrónica de Investigación Educativa, 4 (1).

García Garrido, J. L. (1992). Problemas mundiales de la educación. Nuevas perspectivas. Madrid: Dykinson.

Fernández Enguita, M. (2017a). “Prólogo”. En: Luengo Horcajo F; Moya Otero, J. Mejoras educativas en España. Madrid: Anaya. 
Lopes Louro, G. (2001). O corpo educado: Pedagogias da sexualidade. Belo Horizonte: Autêntica.

Perrenoud, P. (2004a). Desarrollar la práctica reflexiva en el oficio de enseñar. Barcelona: Graó.

Pérez-González, A. B. (2007). “'Atreverse a pensar, a perderse?”. La condición posmoderna de las cosas educativas y de la vida universitaria. Tavira, Revista de Ciencias de la Educación, 23: 149-173. Disponible en: http://cort.as/vY4y

Pujadas, J. J. (2000). El método biográfico y los géneros de la memoria. Revista de Antropología Social, 2000 (9): 27-158.

Torres Santomé, J. (1994). El currículum oculto. Madrid: Morata.

Torres, R. M. (1999). Nuevo rol docente: ¿qué modelo de formación para qué modelo educativo?. En: Aprender para el futuro: nuevo marco de la tarea docente. Madrid: Fundación Santillana. 